\title{
Fluorine atom influence on intramolecular hydrogen bonding, isomerization and methyl group rotation in fluorinated acetylacetones
}

Brett De Vries and Mark Muyskens*

Department of Chemistry and Biochemistry, Calvin College, Grand Rapids, MI 49546, USA

* Corresponding author. E-mail address: mark.muyskens@calvin.edu (M. Muyskens)

\section{Keywords}

photoelimination; proton transfer; resonance-assisted hydrogen bond; density functional calculations; methyl rotation coupling

\section{Abstract}

1-fluoro-pentane-2,4-dione (monofluoroacetylacetone, MFAA) is an asymmetric $\beta$-diketone with a strong intramolecular hydrogen bond similar to acetylacetone (AA) and its fluorinated analogs 1,1,1trifluoro- (TFAA), and 1,1,1,5,5,5-hexafluoroacetylacetone (HFAA). The presence of a fluorine atom in MFAA has the potential to open an HF elimination channel in its gas-phase photochemistry motivating this study of MFAA hydrogen bonding by computer modeling using Density Functional Theory (DFT). As a context, we also report DFT modeling of AA and selected fluorinated acetylacetones: 1,1-difluoropentane-2,4-dione (difluoroacetylacetone, DFAA), TFAA, and HFAA. The most stable molecular structure for all three asymmetric $\beta$-diketones (MFAA, DFAA and TFAA) is the isomer with the fluoromethyl group proximal to the carbonyl carbon; in comparison to the proton transfer isomer, which has the fluoromethyl group proximal to the hydroxyl carbon, the carbonyl isomer is lower in energy by 5.1-5.5 kJ mol ${ }^{-1}$ (B3LYP/cc-pVTZ) and 2.1-3.7 kJ mol ${ }^{-1}$ (MP2/Aug-cc-pVTZ). We also report hydrogen bond strengths, barriers to proton transfer interconversion and barriers to rotation of the methyl/fluoromethyl groups. Our study, the first to report molecular structure information on MFAA and DFAA, indicates that the most stable chelated isomer of MFAA is not the structure with the strongest hydrogen bond as conventionally determined. Our modeling also reveals a coupling between proton transfer isomerization and methyl group rotation, and an unexpected double-minimum potential for the rotation of the fluoromethyl group of MFAA. 
Graphical Abstract

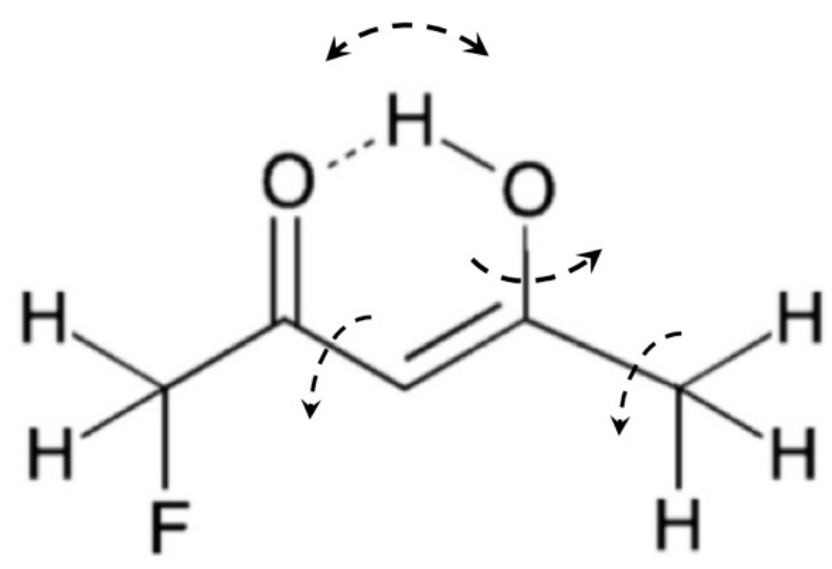




\section{Introduction}

The group of compounds known as $\beta$-diketones are well-known to exist in a keto-enol equilibrium[1,2]. This equilibrium depends on the properties of the substituents on the chelated ring of the enol form[3]. The simplest $\beta$-diketone, pentane-2,4-dione (acetylacetone or AA) and its readily available fluorinated analogs, 1,1,1-trifluoro-pentane-2,4-dione (trifluoroacetylacetone, TFAA) and 1,1,1,5,5,5-hexafluoro-pentane-2,4-dione (hexafluoroacetylacetone, HFAA) all favor the enol form, which is known to exhibit a strong intramolecular hydrogen bond[4-7]. In fact the hydrogen bond (HB) in these molecules is on the order of three times stronger than the HB found in water, a phenomenon tied directly to the degree of conjugation in the chelated ring such that it is termed a resonance-assisted hydrogen bond (RAHB)[6]. Although the presence of trifluoromethyl groups on the chelated ring weakens the HB, the enol form remains dominant in the gas phase. Recently Muyskens et al.[8] showed that both TFAA and HFAA undergo gas-phase HF elimination upon UV excitation, whereas the analogous $\mathrm{H}_{2}$ elimination pathway in AA is not evident. Further understanding of the role that fluorine atoms play in the HB strength and the HF elimination pathway leads to our interest in 1-fluoro-pentane2,4-dione (monofluoroacetylacetone, MFAA), which is the focus of this paper. A more general question is directed at $\beta$-diketones made asymmetric by the addition of fluorine atoms and how that influences the molecular structure and the orientation of the intramolecular hydrogen bond, IHB. We are ultimately curious about whether the molecular structure of MFAA will be poised to undergo the photochemical pathway, since it is possible that the presence of a single fluorine atom in a methyl group is sufficient to open this channel. In the case of an asymmetric acetylacetone, we wonder if the most stable molecular structure will require proton transfer as a necessary first step in the photoelimination mechanism?

Figure 1 shows the molecular structure of MFAA including the atom numbering scheme and the relevant interconversion of structures due to three adjustments: proton transfer shifting the position of the IHB, rotation about the $\mathrm{C}-\mathrm{O}$ bond to open the IHB in order to calculate the $\mathrm{HB}$ energy, and rotation of the fluoromethyl group. Figure $1 \mathrm{~b}$ illustrates the key energy differences that characterize the structures. While the primary focus in this report is on MFAA, we include 1,1-difluoro-pentane-2,4dione (difluoroacetylacetone, DFAA) in our calculations to further explore the influence of fluorine atoms on the HB strength. For context, we also calculated the structural information for the well-studied AA, TFAA and HFAA. As such, our report describes five molecules, three of which involve an 
asymmetric fluorine distribution and therefore will have two distinct isomers, one more stable than the other depending on the orientation of the HB; Scheme 1 lists the eight structures reported in this study.

The questions then are which isomer with an asymmetric fluorine distribution will be favored, and is the strength of the HB simply related to the number of fluorine atoms? Scheme 2 shows the proposed mechanism for the gas phase photoelimination reaction of TFAA and HFAA reported by Muyskens et al.[8] adapted for MFAA. In this scheme, the orientation of the IHB is such that proton transfer is not required before $\mathrm{C} 2-\mathrm{C} 3$ rotation brings the fluorine atom into proximity of the proton leading to elimination. We note that in this configuration the fluoromethyl group is bound to the carbonyl carbon; we therefore refer to this as the carbonyl isomer (also labeled 2MFAA or 2DFAA), and proton transfer to the opposite oxygen atom results in the fluoromethyl group being bound to the hydroxyl carbon (in this case the carbonyl carbon is C4 and we use the labels 4MFAA and 4DFAA). When this labeling approach is applied to TFAA, our labels are in fact consistent with other reports on TFAA modeling† [9-11].

Footnote

$\dagger$ We note that Raissi's structure labeled 5-TFAA[10] and our 4TFAA structure are the same, and Figure 1 of Tabrizi[11] has the 2TFAA/4TFAA notation incorrectly reversed. 

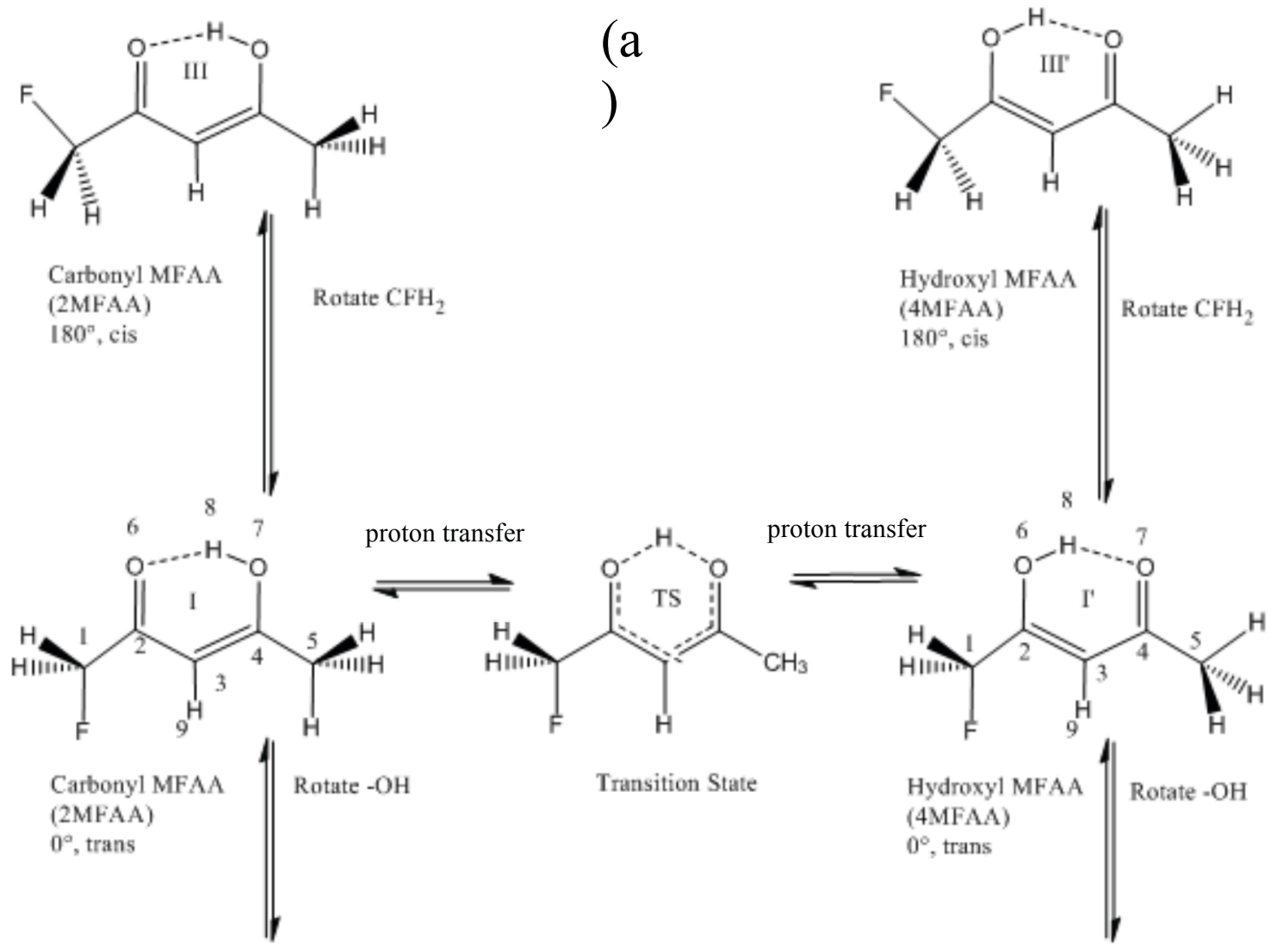<smiles>[CH]C([CH])C(=O)/C=C(/[CH2])O</smiles><smiles>[CH][C@H](C=O)C=C(O)[C@H]([CH])F</smiles>

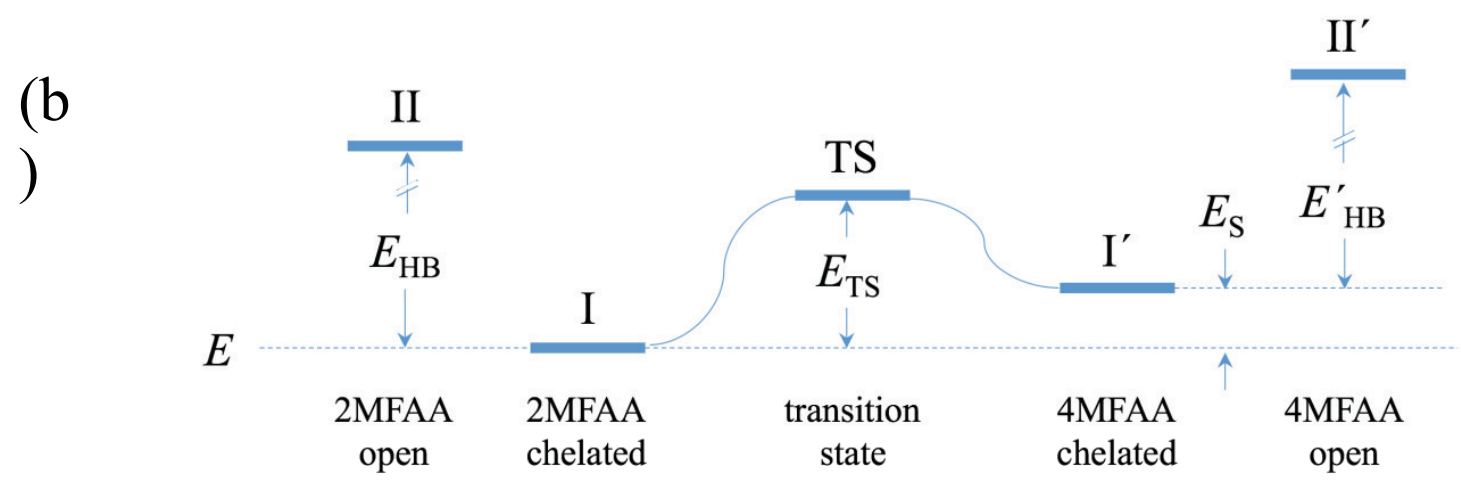

Figure 1: Diagram illustrating the calculated structures for MFAA as representative for all calculated structures. (a) Molecular structures including the numbering and labeling schemes. In all structures the fluoromethyl group remains attached to $\mathrm{C} 2$. The proton shift via the transition state connecting I to I' results in a shift of the carbonyl group from $\mathrm{C} 2$ to $\mathrm{C} 4$. The connection between structure I and II is rotating the $\mathrm{OH}$ group 180 degrees; the connection between structure I and III is rotating the fluoromethyl group to observe the rotation barrier(s). The prime indicates structures where $\mathrm{C} 4$ is the carbonyl carbon - in this case the label for the molecule has a prefix 4, for example 4MFAA. Trans refers to the staggered dihedral orientation of $\mathrm{F}$ with respect to $\mathrm{O}$ across the $\mathrm{C} 1-\mathrm{C} 2$ bond; (b) a scheme representing the relevant energy levels, $E_{\mathrm{S}}$ is the energy by which $\mathrm{I}$ is more stable than $\mathrm{I}^{\prime}, E_{\mathrm{TS}}$ is the barrier for proton transfer from $\mathrm{I}$ to $\mathrm{I}^{\prime}$, and $E_{\mathrm{HB}}$ is the energy of the hydrogen bond $\left(E_{\mathrm{II}}-E_{\mathrm{I}}\right)$. 


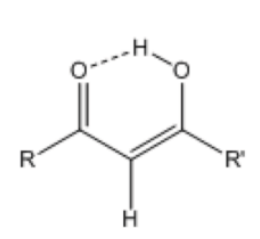

\begin{tabular}{lll} 
Molecule & \multicolumn{1}{c}{$\mathrm{R}$} & \multicolumn{1}{c}{$\mathrm{R}^{\prime}$} \\
AA & $\mathrm{CH}_{3}$ & $\mathrm{CH}_{3}$ \\
2MFAA & $\mathrm{CFH}_{2}$ & $\mathrm{CH}_{3}$ \\
4MFAA & $\mathrm{CH}_{3}$ & $\mathrm{CFH}_{2}$ \\
2DFAA & $\mathrm{CF}_{2} \mathrm{H}$ & $\mathrm{CH}_{3}$ \\
4DFAA & $\mathrm{CH}_{3}$ & $\mathrm{CF}_{2} \mathrm{H}$ \\
2TFAA & $\mathrm{CF}_{3}$ & $\mathrm{CH}_{3}$ \\
4TFAA & $\mathrm{CH}_{3}$ & $\mathrm{CF}_{3}$ \\
HFAA & $\mathrm{CF}_{3}$ & $\mathrm{CF}_{3}$
\end{tabular}

Scheme 1. Diagram indicating the eight structures modeled in this report<smiles>CC1=CC(=O)C(C)O1</smiles>

Scheme 2. Monofluoroacetylacetone (MFAA) photoedecomposition mechanism to eliminate hydrogen fluoride and form methylfuranone. (The * indicates MFAA with additional energy from photon absorption.)

Although MFAA has been synthesized[12-14], it is very sparsely reported in the literature and there are no known commercial suppliers. NMR data suggests MFAA is $87 \%$ enol in the liquid phase ${ }^{10}$, but no IR data or other structural information is available. DFAA is modestly more represented and has commercial sources, however very little experimental data is reported, notably no IR data. Furthermore, there are no known computational studies of the structure of these two molecules. Since the literature reports good agreement between experimental and theoretical results for AA, TFAA, and HFAA[11,15,16] we expect our theoretical results for MFAA and DFAA regarding geometric parameters, hydrogen bonding, IR spectroscopy, isomerization, and barriers to rotation will be useful for characterizing the molecular structure and interpreting future experimental data.

One of the goals of this study is to determine where MFAA and DFAA fit in the trend of hydrogen bond strengths reported by Tabrizi et al.[11]:

$$
\text { AA }>\text { TFAA }>\text { HFAA }
$$


Our results are generally consistent with the idea that as the number of fluorine atoms increases, the intramolecular hydrogen bond strength decreases, but connecting HB energy to the most stable molecular structure is a more complex story than expected. In the process of carrying out this modeling, the results point to two interesting results involving methyl group rotation. First, the models, based on our B3LYP-DFT calculations, indicate that the orientation of the methyl group changes on proton transfer interconversion of the HB, suggesting a coupling between these two molecular motions. Second, the results reveal an unexpected double minimum energy profile for fluoromethyl group rotation in MFAA.

\section{Method of analysis}

All quantum chemistry calculations were performed with the Gaussian09 program package[17] using the WebMO interface[18]. Full geometry optimizations of all eight stable structures investigated in this paper (AA, 2MFAA, 4MFAA, 2DFAA, 4DFAA, 2TFAA, 4TFAA, and HFAA; see Figure 1), their non-hydrogen-bonded counterparts, and their transition states to interconversion were performed using the B3LYP methodology[19-21] and the cc-pVTZ basis set. We did comparison calculations for checking consistency of results at the B3LYP/cc-pVDZ level. The barriers to methyl/halomethyl rotation were calculated for the eight structures of interest at the B3LYP/cc-pVTZ level (and for consistency also at the B3LYP/cc-pVDZ level). We also evaluated the single-point energy for the optimized structures of all eight cases, the corresponding transition states for proton transfer, and the non-hydrogen-bonded counterparts using the MP2/Aug-cc-pVTZ level of theory with the understanding that energy differences using this level of theory are nearly free of basis set superposition error, BSSE. Buemi[22] states that the BSSE effect that is of great concern for intermolecular H-bonding is not as significant a problem when considering intramolecular cases, in particular for the hexatomic chelate ring. Jensen[23] reports some concern about an intramolecular BSSE but does point out that the larger basis sets minimize the effect and the compensation strategy is difficult.

To find structures II and II' of Figure 1, the structure was created with the hydrogen bond in the open configuration, and then optimized at the B3LYP/cc-pVTZ level of theory to find a local minimum that left the structure open (also verified at the B3LYP/cc-pVDZ level). 
The Supplementary Material provides the full set of geometric parameters at both the B3LYP/cc-pVTZ and the B3LYP/cc-pVDZ level to allow comparison of basis set results (Table S1). In general, the geometries from cc-pVDZ to cc-pVTZ are quite comparable. Included in the Supplementary Material are the full set of harmonic vibrational modes calculated at the B3LYP/cc-pVTZ level for both isomers of MFAA (Table S2 and S3), as well as the rotational profiles calculated at the B3LYP/ccpVTZ level of the $\mathrm{CFH}_{2}$ groups of the keto and enol forms of fluoroacetone (1-fluoro-2-propanone) (Figure S1 and S2) discussed in section 3.4.

Table 1

Selected calculated geometric parameters for $\mathrm{AA}^{\mathrm{a}}, \mathrm{HFAA}^{\mathrm{a}}$, and both isomers of MFAA, DFAA, and TFAA, the carbonyl isomer values are highlighted in bold ${ }^{\mathrm{b}}$.

\begin{tabular}{ccccccccc}
\hline & AA & $\begin{array}{c}\text { Carbonyl } \\
\text { 2MFAA }\end{array}$ & $\begin{array}{c}\text { Hydroxyl } \\
\text { 4MFAA }\end{array}$ & $\begin{array}{c}\text { Carbonyl } \\
\text { 2DFAA }\end{array}$ & $\begin{array}{c}\text { Hydroxyl } \\
\text { 4DFAA }\end{array}$ & $\begin{array}{c}\text { Carbonyl } \\
\text { 2TFAA }\end{array}$ & $\begin{array}{c}\text { Hydroxyl } \\
\text { 4TFAA }\end{array}$ & HFAA \\
\hline$R_{2-3}$ & 1.440 & $\mathbf{1 . 4 2 8}$ & 1.360 & $\mathbf{1 . 4 2 5}$ & 1.356 & $\mathbf{1 . 4 2 2}$ & 1.354 & 1.437 \\
$R_{3-4}$ & 1.367 & $\mathbf{1 . 3 7 1}$ & 1.443 & $\mathbf{1 . 3 7 1}$ & 1.449 & $\mathbf{1 . 3 7 5}$ & 1.452 & 1.358 \\
$R_{2-6}$ & 1.244 & $\mathbf{1 . 2 4 5}$ & 1.323 & $\mathbf{1 . 2 4 1}$ & 1.320 & $\mathbf{1 . 2 3 7}$ & 1.316 & 1.228 \\
$R_{7-4}$ & 1.323 & $\mathbf{1 . 3 2 1}$ & 1.244 & $\mathbf{1 . 3 2 1}$ & 1.240 & $\mathbf{1 . 3 1 7}$ & 1.239 & 1.314 \\
$R_{\mathrm{O} \cdots \mathrm{O}}$ & 2.533 & $\mathbf{2 . 5 4 1}$ & 2.526 & $\mathbf{2 . 5 6 1}$ & 2.536 & $\mathbf{2 . 5 4 9}$ & 2.536 & 2.575 \\
$R_{\mathrm{O}-\mathrm{H}}$ & 1.006 & $\mathbf{1 . 0 0 4}$ & 1.008 & $\mathbf{0 . 9 9 9}$ & 1.005 & $\mathbf{1 . 0 0 1}$ & 1.005 & 0.996 \\
$R_{\mathrm{H} \cdots \mathrm{O}}$ & 1.614 & $\mathbf{1 . 6 2 8}$ & 1.607 & $\mathbf{1 . 6 5 7}$ & 1.627 & $\mathbf{1 . 6 4 2}$ & 1.629 & 1.692 \\
$\theta_{6-8-7}$ & 149.6 & $\mathbf{1 4 9 . 0}$ & 149.1 & $\mathbf{1 4 8 . 2}$ & 148.0 & $\mathbf{1 4 8 . 2}$ & 147.7 & 145.4 \\
$\varphi_{\mathrm{X}-1-2-3}$ & 176.4 & $\mathbf{0 . 1}$ & 0.0 & $\mathbf{7 5 . 6}$ & 10.3 & $\mathbf{0 . 0}$ & 0.0 & 180.0 \\
$\varphi_{\mathrm{X}-5-4-3}$ & 0.1 & $\mathbf{0 . 0}$ & 180.0 & $\mathbf{0 . 2}$ & 178.4 & $\mathbf{0 . 0}$ & $180.0^{\mathrm{c}}$ & 0.0 \\
$\lambda^{\mathrm{c}}$ & 0.738 & $\mathbf{0 . 7 0 8}$ & 0.753 & $\mathbf{0 . 7 0 9}$ & 0.770 & $\mathbf{0 . 6 9 8}$ & 0.773 & 0.758 \\
\hline
\end{tabular}

${ }^{\text {a }}$ Note that in the most stable, optimized structures of AA and HFAA, the carbonyl-side methyl/fluoromethyl group eclipses the carbonyl oxygen atom; the hydroxyl-side methyl/fluoromethyl group is staggered with respect to the hydroxyl oxygen atom - best represented by structure I'.

${ }^{\mathrm{b}}$ Distances $R$ in angstroms, angle $\theta$ and dihedral $\varphi$ in degrees, both calculated at the B3LYP/cc-pVTZ level

${ }^{\mathrm{c}}$ In the case of the dihedral angle involving a CF3 group, an angle of $180^{\circ}$ could be equivalently designated $60^{\circ}$. 
${ }^{c} \lambda$ is the unitless Gilli coupling parameter[6], see text 


\section{Results and discussion}

\subsection{Geometrical parameters}

Table 1 presents selected parameters from the optimized geometry for the eight structures of interest (either structure I or I' in Figure 1) at the B3LYP/cc-pVTZ level. The calculated results show that six of the eight structures of interest have $C_{s}$ or nearly- $C_{s}$ symmetry. Concerning the two isomers that do not have $\mathrm{C}_{\mathrm{s}}$ symmetry comprising both isomers of DFAA, the fluorine and hydrogen atoms of the $\mathrm{CF}_{2} \mathrm{H}$ groups are considerably out of the plane formed by the chelated ring. For molecules with $\mathrm{C}_{\mathrm{s}}$ symmetry, the methyl/fluoromethyl groups are normally staggered with respect to the vicinal oxygen atom; exceptions to this are found in AA, 4MFAA, 4TFAA where the $\mathrm{CH}_{3}$ group adjacent to the $\mathrm{C}=\mathrm{O}$ group eclipses the oxygen atom, and analogously the $\mathrm{CF}_{3}$ group adjacent to the $\mathrm{C}=\mathrm{O}$ group of HFAA eclipses the oxygen atom. This feature is represented in Figure 1 by the orientation of the methyl group in structure I'. The dihedral angles in Table $1 \varphi_{\mathrm{X}-1-2-3}$ (also referred to when appropriate as $\varphi_{\mathrm{c}}$ when this dihedral angle is with respect to the carbonyl group) and $\varphi_{\mathrm{X}-5-4-3}$ (referred to later as $\varphi_{\mathrm{h}}$ when this dihedral angle is with respect to the hydroxyl oxygen) give the methyl group orientations, and will be discussed in section 3.4.

The ring conjugation coupling parameter $\lambda$, introduced by Gilli et al.[6], is used to evaluate the degree of $\pi$-delocalization within the chelated ring. It is based on differences between single and double bond lengths in the ring, and is defined as follows:

$$
\lambda=12 *[1-(10.320 *((R 2-6-R 7-4)+(R 3-4-R 2-3)))]
$$

Values of $\lambda$ range from 0 to 1 , where 0 and 1 correspond to no $\pi$-delocalization and 0.5 corresponds to complete $\pi$-delocalization. Table 1 includes these values for the eight modeled structures. With values ranging from 0.70 to 0.77 , it is clear that all exhibit a considerable degree of conjugation. As such, all of the I and I' structures calculated in this study are considered to be stabilized by a resonance-assisted hydrogen bond (RAHB). The effect of fluorine atoms on the conjugation is apparent; in particular, when the fluoromethyl group is adjacent to the $\mathrm{C}=\mathrm{O}$ group, there is a higher degree of conjugation. $\lambda(2 \mathrm{TFAA})$ is closer to 0.5 than $\lambda$ (4TFAA), which points to greater conjugation present in 2TFAA where the $\mathrm{CF}_{3}$ group is bonded to the carbonyl carbon C2. In this case, the difference between 2TFAA and 4TFAA is $\Delta \lambda=0.075$. In MFAA we observe also that $\lambda(2 \mathrm{MFAA})$ is closer to 0.5 than $\lambda(4 \mathrm{MFAA})$ again 
contributing to more conjugation when the fluoromethyl group is bonded to the carbonyl carbon $\mathrm{C} 2$, but the effect is not as large as in TFAA, as expected for the influence of one fluorine atom versus three. And for MFAA the difference between the two isomers is also not as large as TFAA, $\Delta \lambda=0.045$. The coupling parameter appears to show how fluorine atoms influence the degree of conjugation in the chelated ring. Since the set of molecules that are the focus of this study all contain RAHBs, it would seem that strong conjugation will give a stronger HB. But we also expect that as we add $\mathrm{F}$ atoms the HB is weakened, so in seeking to understand which isomer is most stable and how the HB plays a role, these ideas seem to point in opposing directions.

Table 2

Energy, relative to the most stable (carbonyl) isomer structure, of the less stable (hydroxyl) isomer structure, $E_{\mathrm{S}}$, and the proton transfer transition state, $E_{\mathrm{TS}}$, for AA, MFAA, DFAA, TFAA, and HFAA

\begin{tabular}{|c|c|c|c|c|}
\hline \multirow[t]{2}{*}{ Compound } & \multicolumn{2}{|c|}{$E_{\mathrm{S}}\left(\mathrm{kJ} \mathrm{mol}^{-1}\right)$} & \multicolumn{2}{|c|}{$E_{\mathrm{TS}}\left(\mathrm{kJ} \mathrm{mol}^{-1}\right)$} \\
\hline & $B 3 L Y P / c c-p V T Z$ & $M P 2 / A u g-c c-p V T Z$ & $B 3 L Y P / c c-p V T Z$ & $M P 2 / A u g-c c-p V T Z$ \\
\hline AA & - & - & $9.1^{a}(8.1)^{b}$ & $9.1^{\mathrm{c}}$ \\
\hline MFAA & 5.4 & 3.7 & 12.6 & 11.4 \\
\hline DFAA & 5.5 & 3.3 & 14.2 & 12.8 \\
\hline TFAA & $5.1[5.7]^{\mathrm{d}}$ & 2.1 & $13.9[12.5]$ & 11.7 \\
\hline HFAA & - & - & $13.6\{10.1\}^{\mathrm{e}}$ & 12.9 \\
\hline
\end{tabular}

${ }^{a}$ Data from the authors at the B3LYP /cc-pVTZ calculation level. ${ }^{b}$ data from Ref [24] in parentheses, ${ }^{c}$ data from the authors at the MP2 /Aug-cc-pVTZ calculation level, ${ }^{d}$ data from Ref [10] in brackets. ${ }^{e}$ data from Ref [9] in curly braces. Data from Refs $[9,10,24]$ at the B3LYP/6-31 G** calculation level. 


\subsection{Asymmetric isomer stability and proton transfer interconversion}

Table 2 presents the relative energies of both isomers of the three asymmetric compounds. For the chelated structures of MFAA, DFAA, and TFAA, the carbonyl isomer is calculated as more stable than its respective hydroxyl isomer by $5.4,5.5$, and $5.1 \mathrm{~kJ} \mathrm{~mol}^{-1}$, respectively, using the B3LYP/ccpVTZ level of theory. Our calculation of the same structures at the MP2/Aug-cc-pVTZ level, gives energy differences that are generally lower: $2.1,3.3$, and $3.7 \mathrm{~kJ} \mathrm{~mol}^{-1}$, respectively, with the same prediction that the carbonyl isomer is lower in energy. Whether or not the hydrogen bond is present, the carbonyl isomer is always found to be more stable than its hydroxyl counterpart. The one point of comparison we have with another calculated literature value is at the B3LYP level with a different basis set[10], and using our larger basis set the energy difference between 2TFAA and 4TFAA appears to be smaller. It is remarkable that experiment consistently observes that the carbonyl structure is preferred when our best calculations suggest the energy difference between carbonyl and hydroxyl isomers is rather small. These data answer the key question about asymmetry: in each case the most stable isomer is in the form that is ready to participate in the photoelimination channel. This means that while the mechanism calls for the breaking of the hydrogen bond and rotating about one of the bonds in the conjugated ring, the added step of proton transfer is not required for the majority of gas-phase molecules subject to the photoelimination process.

Table 2 also shows the energy barrier for proton transfer interconversion between the two chelated isomers of AA, MFAA, DFAA, TFAA and HFAA. For the barrier to proton transfer isomerization, the difference between our results and the literature values may be due to our calculations being done at a higher level of theory and/or basis set. The isomerization energy differences calculated at the MP2-level of theory are similar to or smaller than our results at the B3LYP-level. Based on the optimized geometry, it is also interesting to note that for interconversion between one enolic isomer to the other for MFAA, DFAA and TFAA, our modeling predicts that only the methyl group must rotate during proton transfer to achieve the most stable structure (although there is also some slight difluoromethyl twisting indicated for DFAA). To allow visualization of these observations, we have collected images of all the optimized molecular structures including transitions states into one figure placed in the Supplemental Material (including the open structures with no HB). Furthermore, since our modeling includes the transition state, TS, there are two steps in the process: (1) from the carbonyl 
structure to the TS, and (2) from the TS to the hydroxyl structure. We note the proton transfer pathway between the more stable carbonyl structure and the transition state does not predict rotation of either methyl group, and therefore it is the step from transition state to the hydroxyl structure that introduces the apparent need for rotation of the methyl group. We discuss the (fluoro)methyl group rotation energies in section 3.4 .

Table 3

Data highlighting hydrogen bond characteristics: $\mathrm{O} \cdots \mathrm{O}$ interatomic distances, $\mathrm{O}-\mathrm{H}$ distances, $\mathrm{O} \cdots \mathrm{H}-\mathrm{O}$ angles, and infrared $\mathrm{OH}$ stretching frequencies ${ }^{\mathrm{a}}$.

\begin{tabular}{|c|c|c|c|c|}
\hline & $R_{\mathrm{O} \cdots \mathrm{O}}(\AA)$ & $R_{\mathrm{O}-\mathrm{H}}(\AA)$ & $\theta(\mathrm{O} \cdots \mathrm{H}-\mathrm{O})\left({ }^{\circ}\right)$ & $v_{\mathrm{OH}}\left(\mathrm{cm}^{-1}\right)$ \\
\hline AA closed & 2.533 & 1.006 & 148.8 & 2998 \\
\hline AA open & 2.793 & 0.963 & & 3806 \\
\hline 2MFAA closed & 2.541 & 1.004 & 149.0 & 3034 \\
\hline 2MFAA open & 2.798 & 0.963 & & 3803 \\
\hline 4MFAA closed & 2.526 & 1.008 & 149.1 & 2960 \\
\hline 4MFAA open & 2.808 & 0.964 & & 3788 \\
\hline 2DFAA closed & 2.561 & 0.999 & 148.2 & 3116 \\
\hline 2DFAA open & 2.814 & 0.963 & & 3803 \\
\hline 4DFAA closed & 2.536 & 1.005 & 148.0 & 3019 \\
\hline 4DFAA open & 2.812 & 0.966 & & 3768 \\
\hline 2TFAA closed & 2.549 & 1.001 & 148.2 & 3081 \\
\hline 2TFAA open & 2.781 & 0.964 & & 3800 \\
\hline 4TFAA closed & 2.536 & 1.005 & 147.7 & 3024 \\
\hline 4TFAA open & 2.811 & 0.965 & & 3785 \\
\hline HFAA closed & 2.575 & 0.996 & 145.4 & 3196 \\
\hline
\end{tabular}


${ }^{\text {a }}$ calculations performed at the B3LYP/cc-pVTZ level. 


\subsection{Hydrogen bonding}

\subsubsection{Overall geometry}

The literature on hydrogen bonding in enolic $\beta$-diketones is split on the issue of whether the HB is linear or not and whether it is symmetric or not. Table 3 collects molecular parameters related to hydrogen bonding, and it shows the $\mathrm{O} \cdots \mathrm{H}-\mathrm{O}$ angles of all structures are near $150^{\circ}$, where the hydrogen atom is covalently-bonded to one oxygen atom, and hydrogen-bonded to the other. These results are in agreement with the experimental data of Gilli et al.[6], which for AA reports an average intramolecular $\mathrm{O} \cdots \mathrm{H}-\mathrm{O}$ angle of $149^{\circ}$ in the solid phase. Gilli et al.[7] comments on the nonlinearity of the hydrogen bond in the crystal form of AA and again states that this intramolecular angle is about $150^{\circ}$. Our results are not consistent with those found by Andreassen et al.[25], who found the $\mathrm{O} \cdots \mathrm{H}-\mathrm{O}$ angle to be near $175.5^{\circ}$ and the $\mathrm{H}$ atom centrally located for HFAA through electron diffraction studies. Our observation of an asymmetrical hydrogen bond is consistent with the results of Woodford et al.[26] who studied hydrogen bonding in malonaldehyde. Iijima reported an asymmetric HB for AA[27], but a symmetric HB in HFAA[28] based on gas-phase, electron diffraction studies.

For AA, both isomers of TFAA, and HFAA, our results for the distances $R_{\mathrm{O}-\mathrm{H}}, R_{\mathrm{O}} \cdots \mathrm{H}$, and $R_{\mathrm{O} \cdots \mathrm{O}}$ are in good agreement with those calculated by Buemi[9], Raissi et al.[10], and Tabrizi et al.[11]. For all calculated structures, the hydrogen atom was found to be located very close to $1 \AA$ from the oxygen atom of $\mathrm{C}-\mathrm{OH}$ and to a somewhat more variable degree just over $1.6 \AA$ from the oxygen atom of $\mathrm{C}=\mathrm{O}$. At the B3LYP/cc-pVTZ level of our study, the O $\cdots \mathrm{O}$ interatomic distances of AA and HFAA are calculated to be 2.533 and $2.575 \AA$, respectively, which are in excellent agreement with that of Tabrizi et al.[11]. Furthermore, our results are in good agreement with the experimental structure determination for AA by electron diffraction[27], that reports an $\mathrm{OH}$ distance of $1.05 \AA$ and an $\mathrm{O} \cdots \mathrm{O}$ distance of $2.51 \AA$. This gives us some degree of confidence that applying our modeling to MFAA and DFAA is valid. 


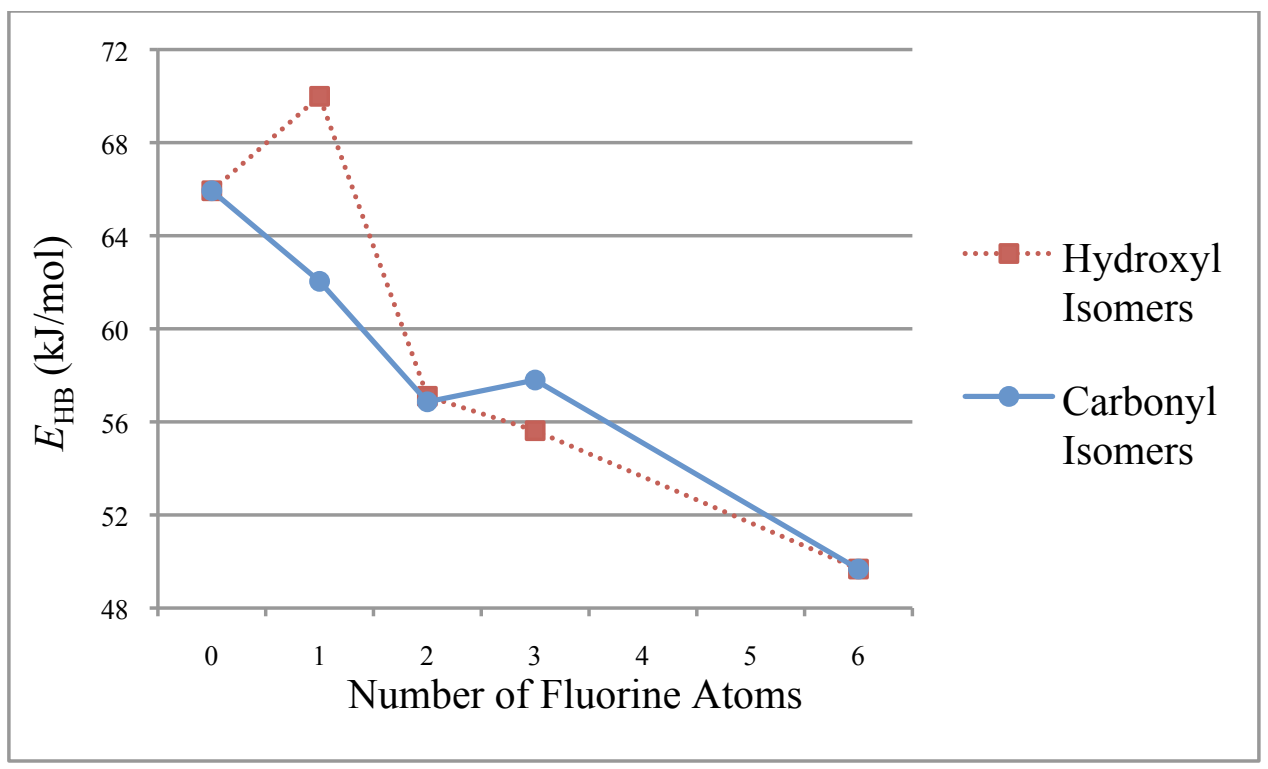

Fig. 2. The energy of hydrogen bonds $\left(E_{\mathrm{HB}}\right)\left(\mathrm{kJ} \mathrm{mol}^{-1}\right)$ of the eight structures of this investigation as a function of the number of fluorine atoms in the molecule (calculated at B3LYP/cc-pVTZ level). Lines connect the data points to guide the eye.

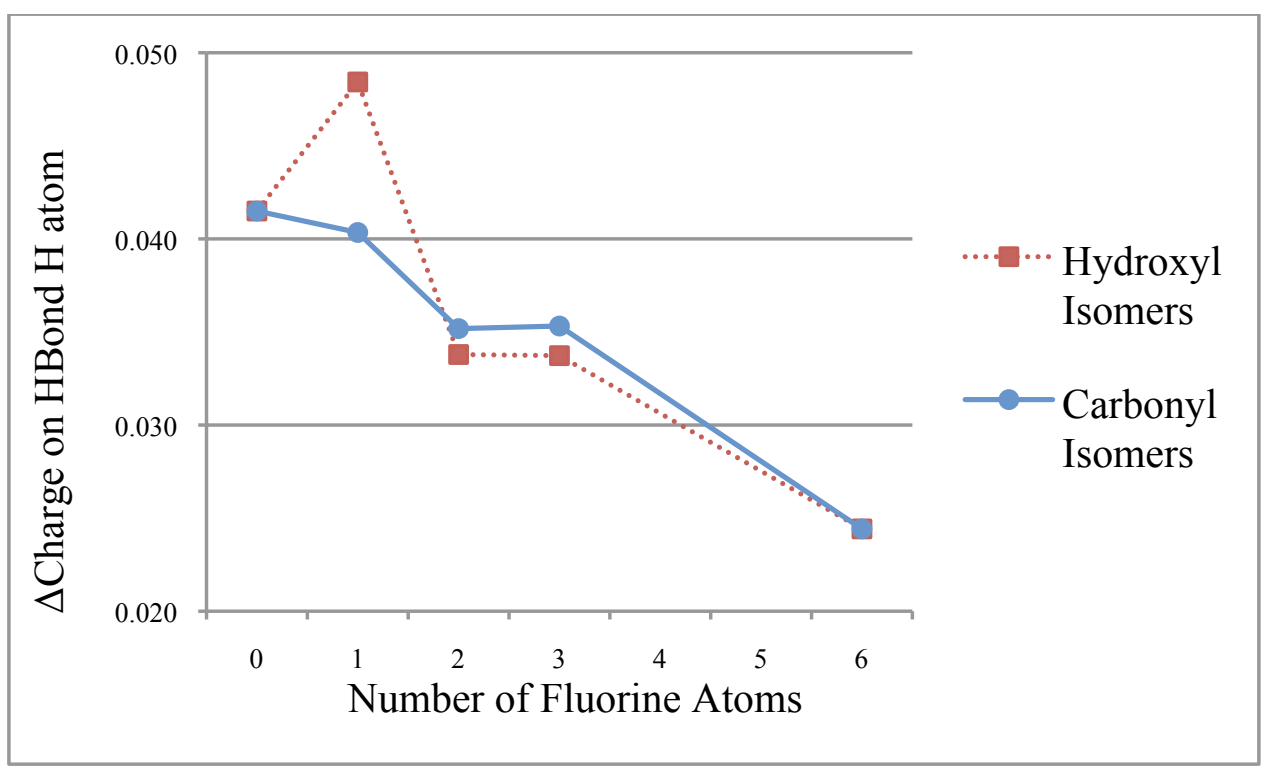

Fig. 3. The change in natural bond order partial charge of the $\mathrm{H}$ atom in the hydrogen-bond (atom 8 in Figure 1) between states I and II, and I' and II' calculated at the B3LYP/cc-pVTZ level of theory. Lines connect the data points to guide the eye. 


\section{Table 4}

Hydrogen bond strength energies, $E_{\mathrm{HB}}$, (the energy difference between structures I and II in Fig. 1) based on three different levels of theory.

\begin{tabular}{cccc}
\hline & \multicolumn{3}{c}{$E_{\mathrm{HB}}\left(\mathrm{kJ} \mathrm{mol}^{-1}\right)$} \\
\cline { 2 - 4 } AA & B3LYP/cc-pVDZ & B3LYPcc-pVTZ & MP2/Aug-cc-pVTZ \\
\hline 2MFAA & 72.6 & 65.9 & 63.9 \\
4MFAA & 68.3 & 62.0 & 60.5 \\
& 76.9 & 70.0 & 68.6 \\
2DFAA & 63.6 & 56.9 & 54.6 \\
4DFAA & 60.8 & 57.1 & 56.4 \\
& & & \\
2TFAA & 61.8 & 57.8 & 56.4 \\
4TFAA & 60.1 & 55.6 & 55.1 \\
& & & 50.4 \\
HFAA & 48.0 & 49.7 & \\
\hline
\end{tabular}

\subsubsection{Hydrogen bond energy}

Table 4 shows our hydrogen bond energy data for all eight structures in this report calculated at three levels of theory. Our values for AA and both TFAA isomers are in very good agreement with those of Tabrizi et al.[11]. According to Perrin et al.[29], hydrogen bonds deemed 'strong' have a strength of $40.0 \mathrm{~kJ} \mathrm{~mol}^{-1}$ or greater. Our hydrogen bond energies cover a range of $65.9 \mathrm{~kJ} \mathrm{~mol}^{-1}$ for AA to $49.7 \mathrm{~kJ}$ $\mathrm{mol}^{-1}$ for HFAA (calculated at the B3LYP/cc-pVTZ level). In general $E_{\mathrm{HB}}$ decreases for each increase in level of theory. The $E_{\mathrm{HB}}$ values become lower by about $1-2 \mathrm{~kJ} / \mathrm{mol}$ comparing B3LYP/cc-vPTZ values to those from MP2/Aug-cc-pVTZ applied to the same structure, but the difference has a tendency to become less as the number of fluorine atoms increases. One unexpected feature in Table 2 is that the HFAA $E_{\mathrm{HB}}$ at the lowest theory level (B3LYP/cc-pVDZ) appears to be lower than the other values, but in this case the pair of geometry-optimized structures (open and closed) do not completely agree with the next higher theory-level. We place more confidence in the B3LYP/cc-vPTZ geometry because it fits the pattern established by the other molecules in this study, especially the other symmetric optimized structure in AA. 
Figure 2 highlights the hydrogen bond energy versus the number of fluorine atoms in the molecule at the B3LYP/cc-pVTZ level. It shows, in general, that the hydrogen bond strengths of the carbonyl isomers decrease as the number of fluorine atoms increases, with 2DFAA exhibiting a small deviation from the trend. The most striking feature of this figure is the large $E_{\mathrm{HB}}$ for 4MFAA; in this case, the less stable hydroxyl isomer appears to have a much stronger hydrogen bond than the carbonyl isomer. This challenges the notion that the isomer with the stronger hydrogen bond, as HBs are conventionally calculated, will be the more stable isomer. In the case of DFAA the two isomers have nearly identical HB energies and yet the carbonyl isomer is more stable, and in the case of TFAA the more stable carbonyl isomer has the stronger HB.

In the non-hydrogen bonded cases of hydroxyl DFAA, hydroxyl TFAA, and HFAA, the hydrogen atom of $\mathrm{C}-\mathrm{OH}$ is now in closer proximity to a fluoromethyl group, which has the potential to create a hydrogen bond with a fluorine atom, most obviously observed in the case of HFAA. This weak hydrogen bond stabilizes the "non-hydrogen bonded" molecule, which results in a smaller apparent hydrogen bond strength. However, in hydroxyl MFAA, the oxygen atom of $\mathrm{C}-\mathrm{OH}$ and the fluorine atom remain staggered, so there is no corresponding $\mathrm{F} \cdots \mathrm{HO}$ hydrogen bond in this case. This may account for the larger apparent hydrogen bond for MFAA-II'. This raises the natural question of whether the method of calculating hydrogen bonds by comparing energies of conformations I and II (see Figure 1) is the right way to calculate the hydrogen bond strength. Since most papers including the work of Tabrizi et al.[11] use the conventional approach, we chose to calculate hydrogen bond strengths in the same manner for comparison's sake.

Supplementary Material Table S4, comprised of the absolute energies for calculating $E_{\mathrm{HB}}$, provides a glimpse of the effect of carrying out the calculations with a basis set that is one level lower than our cc-pVTZ standard basis set. B3LYP/cc-vPTZ absolute energies are always lower than $\mathrm{B} 3 \mathrm{LYP} / \mathrm{cc}-\mathrm{vPDZ}$ absolute energies for the same structure, which is expected from simply expanding the basis set. The resulting hydrogen bond energies, $E_{\mathrm{HB}}$, are also a bit lower by about $10 \%$. MP2/Aug-ccpVTZ absolute energies are always higher (less negative) than either of the B3LYP energies but it is a single point energy for the structure optimized by the B3LYP/cc-vPTZ approach, and in this case the primary interest is the energy differences for determining $E_{\mathrm{HB}}$. The fact that $E_{\mathrm{HB}}$ normally gets smaller with an expanded basis set may also be consistent with a smaller BSSE effect. 


\subsubsection{Natural bond order analysis}

To further investigate the hydrogen bonding of these structures, we ran natural bond order (NBO) population analysis and partial charge assignment on the B3LYP/cc-vPTZ optimized structures. In every case, the hydrogen bonded structures clearly reveal more negative partial charge on the oxygen atoms compared to their corresponding open structures. A prominent observation is the change in partial charge on the $\mathrm{H}$ atom involved in hydrogen bonding (atom 8 in Figure 1). Figure 3 shows the difference in the NBO-calculated partial charge on the proton between the corresponding chelated structures, I or $\mathrm{I}^{\prime}$, and open structures, II or II'; the key here being that the more positive the charge on the hydrogen atom appears to correlate very well with the stronger hydrogen bond. The progression with number of $F$ atoms in Figure 3 is strikingly similar to Figure 2. This once again points to 4MFAA having the strongest hydrogen bond, even though 2MFAA is calculated to be the more stable isomer.

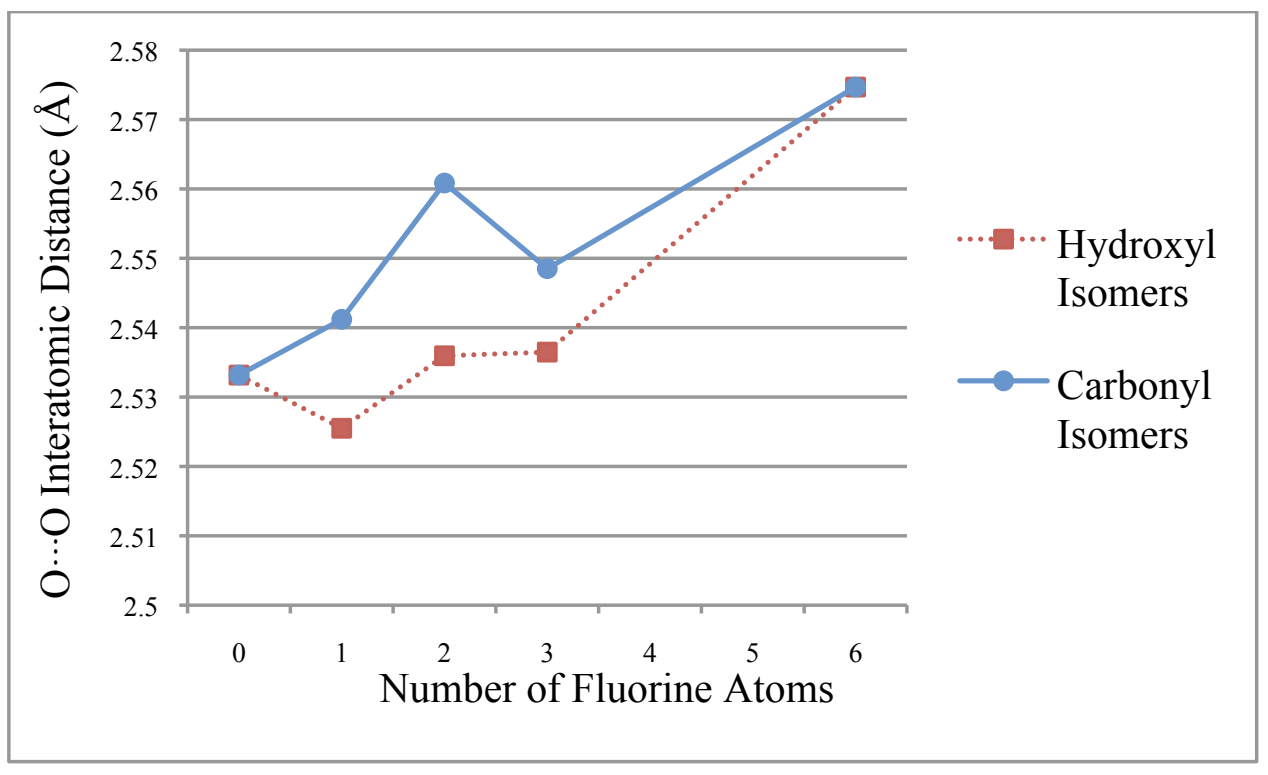

Fig. 4. The $\mathrm{O} \cdots \mathrm{O}$ interatomic distance $(\AA)$ for the eight structures investigated in this paper. 


\subsubsection{O $\cdots$ O interatomic distance}

Figure 4 shows our calculated $R_{\mathrm{O}} \cdots_{\mathrm{O}}$ interatomic distances as a function of the number of fluorine atoms, which gives another perspective on the hydrogen bond since shorter $\mathrm{O} \cdots \mathrm{O}$ interatomic distances normally correspond to stronger hydrogen bonds. Our calculation results for AA, TFAA and HFAA follow the same trend as that of Tabrizi et al.[11]. For the more stable carbonyl isomer, there is a straightforward increase in $R_{\mathrm{O}} \cdots \mathrm{O}$ as fluorine increases, with the exception of DFAA being longer than anticipated with respect to the other values. For the three asymmetric cases, the less stable hydroxyl isomer has a shorter $R_{\mathrm{O}} \cdots \mathrm{O}$ suggesting a stronger $\mathrm{HB}$ than found in the carbonyl isomer. As with Figure 2 and 3 , the story of fluorine addition does not reduce to the simple picture that would allow us to place the molecules in order by decreasing strength of the HB (as calculated here). Nevertheless, Figure 4 does show the overall trend for a weaker HB as the number of fluorine atoms increases.

\subsection{5 $\mathrm{O}-\mathrm{H}$ stretching frequency}

The $\mathrm{O}-\mathrm{H}$ stretching frequency, $v_{\mathrm{O}-\mathrm{H}}$, provides another molecular parameter that indicates a degree of hydrogen bonding. For example, $v_{\mathrm{O}-\mathrm{H}}$ for RAHB-containing malondialdehyde[30] is $3079 \mathrm{~cm}^{-}$ ${ }^{1}$, which is in the range of our data reported in Table 3 (our values range from 2960 to $3116 \mathrm{~cm}^{-1}$ ). The report on malondialdehyde suggests that the $v_{\mathrm{O}-\mathrm{H}}$ would occur at $3622 \mathrm{~cm}^{-1}$ if there was no $\pi-$ conjugation[30]. Pribble, Hagemeister and Zwier[31] observe that, while the methanol monomer $\mathrm{OH}$ stretching frequency occurs at $3681.5 \mathrm{~cm}^{-1}$, hydrogen bonded clusters of methanol ranging from 2 to 6 methanol molecules in the presence of a single benzene molecule exhibit $\mathrm{OH}$ stretching frequency shifts due to hydrogen bonding of -200 to over $-500 \mathrm{~cm}^{-1}$. When we calculate $v_{\mathrm{O}-\mathrm{H}}$ for the open nonhydrogen-bonded structures in this study, the values range from 3760 to $3800 \mathrm{~cm}^{-1}$. It is apparent that our $\mathrm{OH}$ stretching frequencies are shifted dramatically from the $\mathrm{OH}$ stretching frequency expected for a free $\mathrm{OH}$ stretch. For the carbonyl to hydroxyl shift in all three asymmetric cases, the $\mathrm{OH}$ stretching frequency gets further red shifted (by $74 \mathrm{~cm}^{-1}$ for 2MFAA to 4MFAA). The Gilli lambda parameter in Table 1 suggests the carbonyl is somewhat more conjugated than the hydroxyl isomer, so the notion that more conjugation strengthens the $\mathrm{HB}$, which in turn red-shifts the $\mathrm{OH}$ stretching frequency is not borne out. And in Table 3 there does not appear to be a direct correlation between the absolute frequency and the number of fluorine atoms. Nonetheless, the amount of red-shifting of the calculated $\mathrm{OH}$ stretching frequencies points to significant influence of the HB. 
Interestingly, the pattern of shifts in the $\mathrm{OH}$ stretching frequency is very similar to the pattern shown in Figure 3 for the $R_{\mathrm{O} \cdots \mathrm{O}}$ interatomic distances, such that the shortest $R_{\mathrm{O}} \cdots \mathrm{O}$ correlates to the largest $v_{\mathrm{O}-\mathrm{H}}$ red shift, again suggesting the strongest $\mathrm{H}$-bond is present in 4MFAA. Our modeling involves 8 structures with different $\mathrm{O} \cdots \mathrm{O}$ distances, and Figure 5 shows how the calculated $\mathrm{O}-\mathrm{H}$ stretching frequency in the chelated structures appears to be very well correlated to the $\mathrm{O} \cdots \mathrm{O}$ distance. Ratajczak[32] described a general relationship between $\mathrm{O}-\mathrm{H}$ stretching frequency and the $\mathrm{O} \cdots \mathrm{O}$ distance based on dozens of compounds. In the region of $\mathrm{O} \cdots \mathrm{O}$ distances from 2.5 to $2.6 \AA$, Ratajczak's report gives a slope of about $5000 \mathrm{~cm}^{-1} / \AA$ with a fair amount of scatter about this general trend over a much wider range of distances. Our modeling points to a close relationship with a slope of $4600 \mathrm{~cm}^{-1} / \AA$ in the linear fit shown in Figure 5.

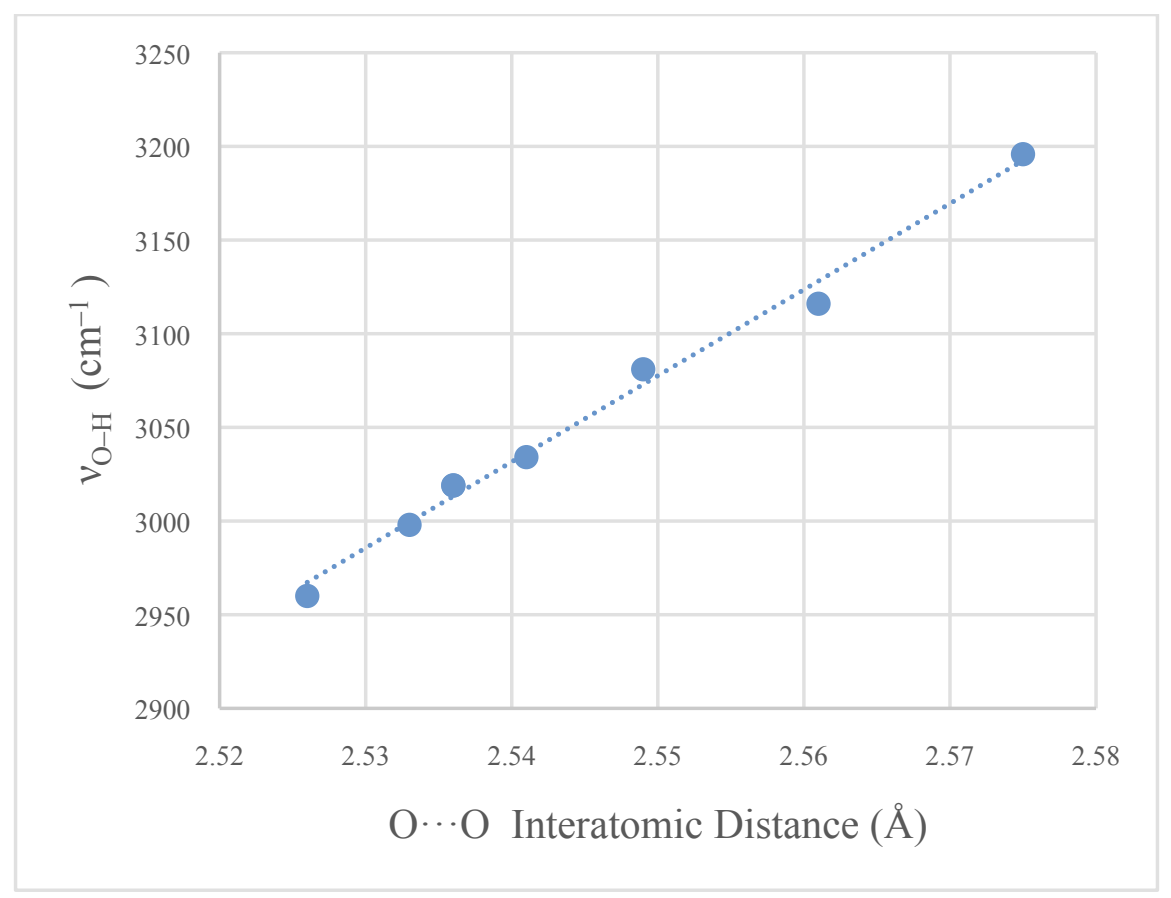

Fig. 5. O-H stretching frequency, $v_{\mathrm{O}-\mathrm{H}}$, versus $\mathrm{O} \cdots \mathrm{O}$ interatomic distance $(\AA)$ for the eight structures modeled in this paper. The dotted line is the linear fit to the data. The shortest distance corresponds to 4MFAA and the longest to HFAA. 
3.4 Barriers to fluoromethyl and methyl rotation in the asymmetric molecules, MFAA, DFAA, and TFAA

As noted earlier, our modeling indicates a coupling between proton transfer interconversion and methyl group rotation. To be sure, this coupling is simply indicated by comparing the optimized structures and noting that the methyl group orientation has changed. This is easiest to point out in the symmetric cases, AA and HFAA, where the carbonyl methyl is eclipsed with respect to the carbonyl oxygen and the hydroxyl methyl is staggered with respect to the hydroxyl oxygen. When proton transfer occurs, both methyl groups must rotate. The asymmetric cases are not as straightforward. For MFAA and TFAA, our modeling indicates that the methyl group will rotate but the fluoromethyl group does not, while in the DFAA case, the methyl group will rotate as in MFAA and TFAA, but there is also some lesser rotation indicated for the $\mathrm{CHF}_{2}$ group. To attempt to determine the strength of this coupling is beyond the scope of this study, except to be curious about the energy required for methyl rotation in the form of a rotation energy profile.

To investigate this further, we modeled the methyl group rotation energy profile for each structure, which reveals the barrier to rotation. Our rotational studies involve starting with the optimized molecular structure and rotating the $\mathrm{X}-\mathrm{C} 1-\mathrm{C} 2-\mathrm{C} 3$ dihedral angle $\left(\varphi_{\mathrm{c}}\right)$ or the $\mathrm{X}-\mathrm{C} 5-\mathrm{C} 4-\mathrm{C} 3$ dihedral angle $\left(\varphi_{\mathrm{h}}\right)$ for 36 steps by $10 \%$ step. The geometry was optimized after every step, while keeping the specified angle fixed. We chose to use dihedral angles oriented along the carbon skeleton instead of dihedral angles that involve the oxygen atom because (a) C3 is the center of the carbon skeleton and thus consistent among all of our models, and (b) usually, the most stable conformation of the molecules occurs at $\varphi_{\mathrm{c}}=0^{\circ}$. AA and HFAA are exceptions; they have relatively small maxima at $\varphi_{\mathrm{c}}=0^{\circ}$. For all barriers to rotation, data are presented at the B3LYP/cc-pVTZ level. We obtained similar results from repeating all the studies at the B3LYP/cc-pVDZ level. For the carbonyl isomers, the dihedral angle $\left(\varphi_{c}\right)$ is computed between F-C1-C2-C3; for the hydroxyl isomers, the dihedral angle $\left(\varphi_{h}\right)$ is computed between F-C5-C4-C3. 


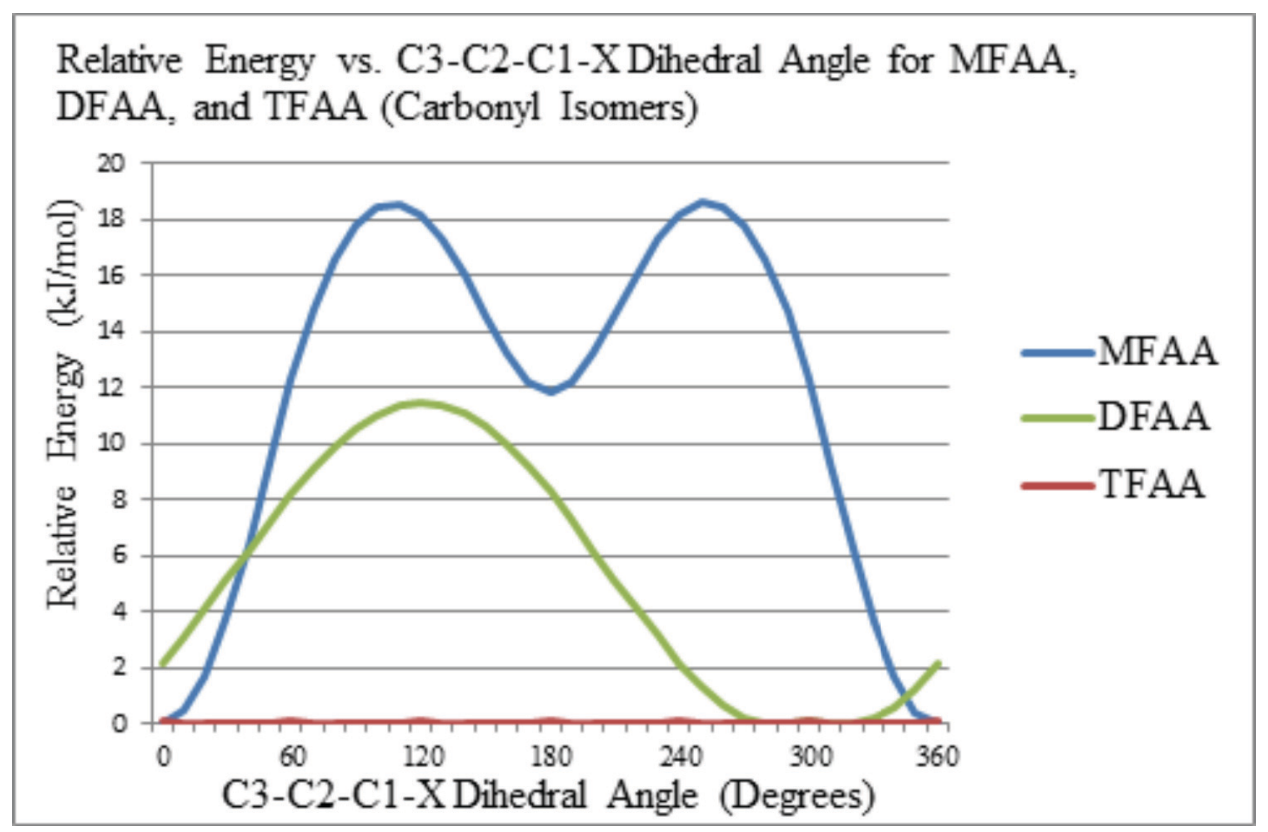

Fig. 6. The barriers to rotation of the fluoromethyl groups of carbonyl MFAA, carbonyl DFAA, and carbonyl TFAA at the B3LYP/cc-pVTZ level.

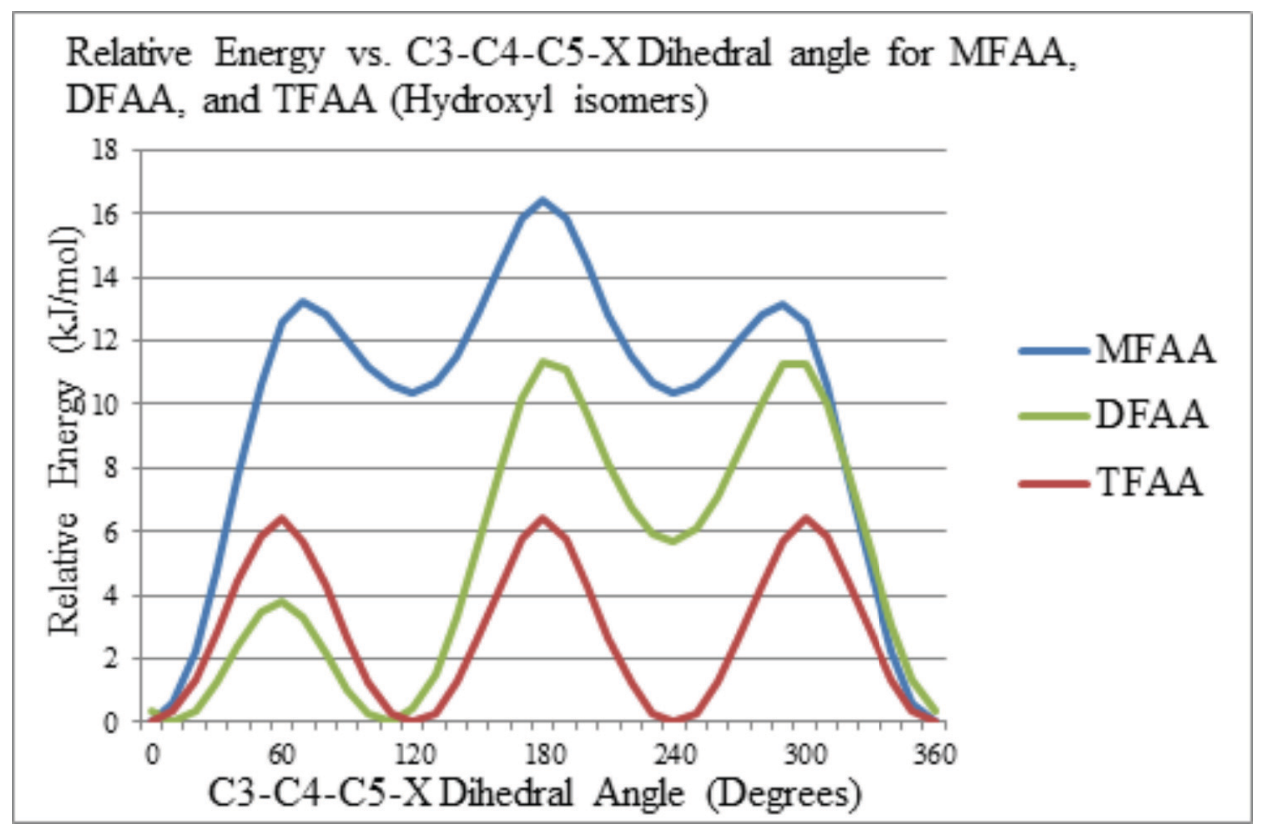

Fig. 7. The barriers to rotation of the fluorinated methyl groups of hydroxyl MFAA, hydroxyl DFAA, and hydroxyl TFAA at the B3LYP/cc-pVTZ level. 
Figure 6 shows the results of complete rotation of the $\mathrm{CFH}_{2}$ group for carbonyl MFAA. The potential energy curve is symmetrical every $180^{\circ}$ and displays a double-minimum potential: the global minimum at $0^{\circ}$ corresponds to the trans-structure (I in Figure 1), and a higher local-minimum at $180^{\circ}$ corresponds to the $c i s$-structure (II). This rotation local minimum at $\varphi_{\mathrm{c}}=180^{\circ}$ is just below $12.0 \mathrm{~kJ} \mathrm{~mol}^{-}$ ${ }^{1}$. The existence of a local minimum with its orientation of $\mathrm{F}$ eclipsing $\mathrm{O}$ and forming a two-fold energy profile is a complete surprise. For carbonyl DFAA involving rotation of the $\mathrm{CF}_{2} \mathrm{H}$ group, Figure 6 reveals also a double-minimum potential although the two minima are barely separated such that it is essentially a single minimum. Based on the geometric arrangements of the $\mathrm{CF}_{2} \mathrm{H}$ and $\mathrm{CH}_{3}$ groups for both the carbonyl and hydroxyl isomers of DFAA, it is evident that both groups must rotate in concert upon proton transfer isomerization to achieve the most stable structure. Also shown in Figure 6 are the results of complete rotation of the $\mathrm{CF}_{3}$ group of carbonyl TFAA, which has a very small (barrier $<0.1 \mathrm{~kJ}$ $\mathrm{mol}^{-1}$ ) and threefold symmetry; minima are observed at angles of $30^{\circ}, 90^{\circ}, 150^{\circ}, 210^{\circ}, 270^{\circ}$, and $330^{\circ}$, which are angles that are not in the plane of the chelated ring, and the potential energy curve is symmetrical every $120^{\circ}$.

Figure 7 shows the results of the complete rotation of the $\mathrm{CFH}_{2}$ group for hydroxyl MFAA. It displays a triple-minimum potential and shows rotation maxima whenever an atom eclipses the oxygen atom of the $\mathrm{C}-\mathrm{OH}$ group. Interestingly, in the case of TFAA, our calculation indicates that the $\mathrm{CH}_{3}$ group has an appreciable barrier to rotation (greater than $4.1 \mathrm{~kJ} \mathrm{~mol}^{-1}$ ) and we note that in the proton transfer process it must rotate. This is in remarkable contrast to the situation with the $\mathrm{CF}_{3}$ group (shown in Figure 6) where it has essentially no rotation barrier and yet it is not required to rotate upon proton transfer.

Focusing on the methyl, $\mathrm{CH}_{3}$, rotation coupled to proton transfer in the asymmetric cases involves paying attention to which HB isomer is used for the calculation. The methyl rotation has barriers of $0.7,1.2$, and $1.3 \mathrm{~kJ} / \mathrm{mol}$ for 4MFAA, 4DFAA and 4TFAA, respectively; whereas the methyl rotation has barriers of 4.6, 4.4, and $4.2 \mathrm{~kJ} / \mathrm{mol}$ for 2MFAA, 2DFAA and 2TFAA, respectively. The rotation profiles of these all have the three-fold symmetry repeated every $120^{\circ}$ similar to the TFAA curve in Figure 7. These are the methyl rotations directly coupled to proton transfer in the asymmetric cases hinted at by our modeling. It appears that the hydroxyl side barriers are more relevant to the coupled motion because the rotation happens as the proton is on the hydroxyl side of the transition state. 


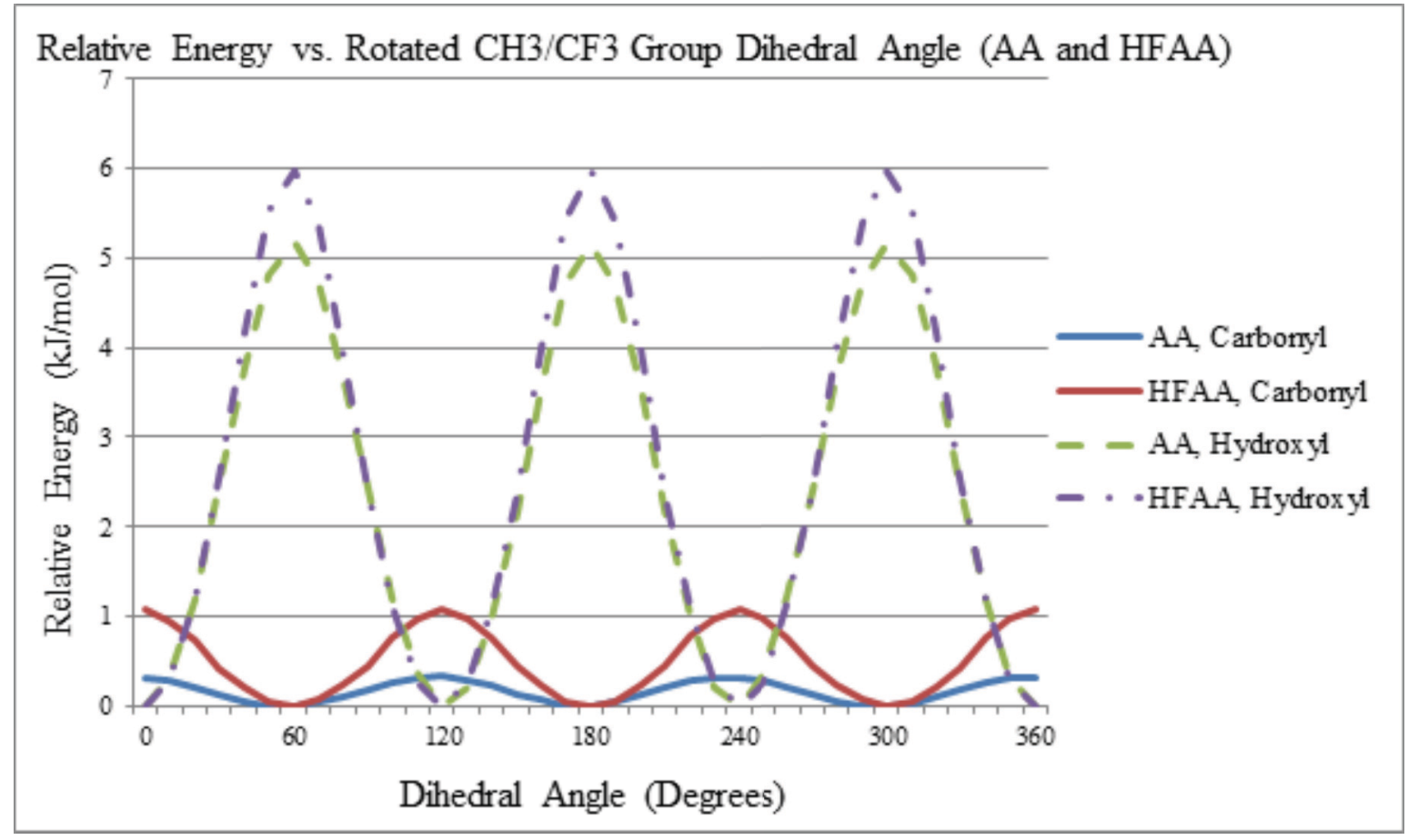

Fig. 8. The barriers to rotation of both $\mathrm{CH}_{3}$ groups in AA and both $\mathrm{CF}_{3}$ groups in HFAA at the B3LYP/cc-pVTZ level.

\subsection{Barriers to methyl rotation of the symmetric molecules, AA and HFAA}

To provide some context to the rotational barriers for the asymmetric case, we also studied the rotational energy profiles for the two symmetric cases. Figure 8 shows the results of complete rotation of the $\mathrm{CH}_{3}$ group on both sides of AA and the $\mathrm{CF}_{3}$ group on both sides of HFAA. The potential energy curves for rotation of the groups on the carbonyl side have threefold symmetry in which the barriers to rotation are small (barrier $<1.1 \mathrm{~kJ} \mathrm{~mol}^{-1}$ ). Figure 8 also displays the potential energy curves for rotation of the groups on the hydroxyl side of AA and HFAA. These results are quite similar to each other: they have three-fold symmetry and have barriers in the $5.0-6.0 \mathrm{~kJ} \mathrm{~mol}^{-1}$ range. These results are similar to the TFAA case, where the carbonyl side has a very low barrier and the hydroxyl side has a barrier circa $6 \mathrm{~kJ}$ $\mathrm{mol}^{-1}$.

All of the barriers to rotation presented here, with the highest barrier being $18.6 \mathrm{~kJ} \mathrm{~mol}^{-1}$ for 2MFAA, we expect to allow essentially unhindered rotation at $25{ }^{\circ} \mathrm{C}$. However, under much colder 
conditions, such as in molecular beams used in microwave spectroscopy, the barriers may be significant enough that some rotations may be hindered.

Our results are in some agreement with that of Caminati et al.[33] who claimed the methyl groups of AA have two distinct and low barriers to rotation, yet only one to be freely rotating. Our barriers to rotation for HFAA are in agreement with the values reported by Evangelisti et al.[16] and Chatterjee et al.[34] which include the results of $\mathrm{CF}_{3}$ rotation for HFAA at the B3LYP/aug-cc-pVDZ level, as well as with other methodologies. The methyl group motion coupling to proton transfer has been studied in HFAA and in AA.[34,35]

Spangler et al.[36] report that substitution on one ring of (E)-stilbene can slightly affect groundstate rotation barriers of a $\mathrm{CH}_{3}$ group on the other ring despite the large distance involved. With this in mind, it is interesting to compare the cases of HFAA and carbonyl TFAA. Both have a $\mathrm{CF}_{3}$ group on $\mathrm{C} 2$, and its barrier to rotation appears to be quite different (from $<0.1$ to $1.1 \mathrm{~kJ} \mathrm{~mol}^{-1}$ ) depending on whether there is a methyl group or a $\mathrm{CF}_{3}$ group bound to $\mathrm{C} 4$. In each case, the same group $\left(\mathrm{CF}_{3}\right)$ is rotated on the carbonyl side of the molecule, but the substitution on the hydroxyl side of the molecule, far from the site of rotation, is the only structural difference from which differences between the two molecules arise. Remarkably, if we make a similar comparison between carbonyl AA and carbonyl TFAA, in which case both have a methyl group at $\mathrm{C} 4$, the carbonyl methyl on AA has a small $\left(\sim 0.3 \mathrm{~kJ} \mathrm{~mol}^{-1}\right)$ barrier, whereas the $\mathrm{CF}_{3}$ group on TFAA has essentially no barrier. Perhaps these differences are not so large at our level of computer modeling that they shouldn't be overemphasized.

The results of rotating $\varphi_{\mathrm{c}}$ for the carbonyl isomer of MFAA exhibits an increase in energy as the fluorine atom gets closer to the $\mathrm{C}=\mathrm{O}$ group. However, the energy reaches its maximum (near $\varphi_{\mathrm{c}}=110^{\circ}$ ), then decreases to a local minimum at $\varphi_{\mathrm{c}}=180^{\circ}$, in which the fluorine atom eclipses the oxygen atom of $\mathrm{C}=\mathrm{O}$. Given the unexpected two-fold energy profile, we also performed the calculation at both the MP2/cc-pVTZ and B3LYP/cc-pVDZ levels and observed the double-minima potential. To see if this profile is unique to MFAA, we did a calculation for the $\mathrm{CFH}_{2}$ group rotation in the keto form of fluoroacetone, and obtained strikingly similar results in terms of barrier height and shape of the energy profile compared to carbonyl MFAA. Our obtained barrier height for fluoroacetone is also in agreement with that previously reported by Durig et al.[37]. It is interesting that $\mathrm{CFH}_{2}$ rotation in carbonyl MFAA gives a two-fold potential energy curve with a local minimum at $\varphi_{\mathrm{c}}=180^{\circ}$, but the same $\mathrm{CFH}_{2}$ rotation for hydroxyl MFAA gives the expected threefold potential energy curve with the global maximum at $\varphi_{\mathrm{h}}$ 
$=180^{\circ}$, the difference being simply that the $\mathrm{F}$ atom is on the opposite side of the conjugated ring. It seems unlikely that sterics play a role in this strikingly different result.

These coupled molecular dynamics potentially play a role in the photoelimination mechanism. We have established that the majority of gas-phase molecules are in the optimal structure of the two hydrogen-bonded isomers for the mechanism to proceed, however in the case that a reasonable fraction of the gas-phase molecules is in the hydroxyl configuration, then the rotation-coupled proton transfer step must be included in the pathway.

\section{Conclusion}

For the sparsely studied MFAA and DFAA, we have characterized by DFT (B3LYP/cc-pVTZ) modeling their molecular structures, which include the remarkably strong intramolecular hydrogen bond. Anticipating interest in the photochemistry of these compounds, we report for both of these asymmetric beta-diketones that the carbonyl isomer (fluoromethyl bound to the carbonyl carbon) is the more stable of the two chelated structures. This is consistent with calculations and experimental data on AA, TFAA and HFAA. The addition of fluorine atoms to the molecule influences the hydrogen bonding and the degree of conjugation in the ring stabilized by the hydrogen bond. The most straightforward approach to determining the hydrogen bond strength (by difference between closed and open forms of the chelated structure) offers a more complicated story juxtaposed with the observation that fluorine weakens the hydrogen bond in the sequence AA, TFAA and HFAA; hydroxyl MFAA has the strongest HB of all structures calculated in this report. Our modeling reveals a coupling between methyl rotation and proton transfer isomerization, and the unexpected two-fold fluoromethyl rotation energy profile of 2MFAA could provide an interesting test of the modeling if it is observable in low temperature experiments. We calculate the barrier to proton transfer from 2MFAA to 4MFAA is $12.6 \mathrm{~kJ} \mathrm{~mol}^{-1}$ (B3LYP/cc-pVTZ) which is comparable to calculated barriers for TFAA and HFAA.

\section{Acknowledgements}

This work was supported by a grant from the National Science Foundation (MRI CHE-0420928). The computations were accomplished using dahl.calvin.edu, a Beowulf cluster built with support from the National Science Foundation's Major Research Instrumentation and Cyber Infrastructure programs (MRI OCI-0722819). We acknowledge Professor Roger DeKock for his guidance, and we acknowledge 
support from the Enno Wolthuis Summer Student Research Fellowship.

Fix Gaussian cite: substitute 'n.d.' for 'Gaussian Inc., Wallingford CT, 2009.'

Fix Webmo cite: substitute 'n.d.' for '(accessed 13 Sep 2016).'

\section{References}

[1] T. Ishida, F. Hirata, S. Kato, Thermodynamic analysis of the solvent effect on tautomerization of acetylacetone: An ab initio approach, J. Chem. Phys. 110 (1999) 3938-3945.

[2] H.P. Upadhyaya, A. Kumar, P.D. Naik, Photodissociation dynamics of enolic-acetylacetone at 266, 248, and $193 \mathrm{~nm}$ : Mechanism and nascent state product distribution of $\mathrm{OH}, \mathrm{J}$. Chem. Phys. 118 (2003) 2590-2598.

[3] N.V. Belova, G.V. Girichev, H. Oberhammer, N.H. Trang, S.A. Shlykov, Tautomeric properties and gas-phase structure of 3-methyl-2,4-pentanedione, J. Mol. Struct. 1023 (2012) 49-54.

[4] J.J. Dannenberg, R. Rios, Theoretical Study of the Enolic Forms of Acetylacetone. How Strong Is the Hydrogen Bond?, J. Phys. Chem. 98 (1994) 6714-6718.

[5] M.-C. Yoon, Y.S. Choi, S.K. Kim, The OH Product State Distribution from the Photodissociation of Hexafluoroacetylacetone, J. Phys. Chem. A. 104 (2000) 4352-4355.

[6] G. Gilli, F. Bellucci, V. Ferretti, V. Bertolasi, Evidence for resonance-assisted hydrogen bonding from crystal-structure correlations on the enol form of the $\beta$-diketone fragment, J. Am. Chem. Soc. 111 (1989) 1023-1028.

[7] P. Gilli, V. Bertolasi, V. Ferretti, G. Gilli, Evidence for resonance-assisted hydrogen bonding. 4. Covalent nature of the strong homonuclear hydrogen bond. Study of the $\mathrm{O}-\mathrm{H} \cdots \mathrm{O}$ system by crystal structure correlation methods, J. Am. Chem. Soc. 116 (1994) 909-915.

[8] K.J. Muyskens, J.R. Alsum, T.A. Thielke, J.L. Boer, T.R. Heetderks, M.A. Muyskens, Photochemistry of UV-excited trifluoroacetylacetone and hexafluoroacetylacetone I: infrared spectra of fluorinated methylfuranones formed by HF photoelimination, J. Phys. Chem. A. 116 (2012) 12305-12313.

[9] G. Buemi, Ab initio DFT study of the hydrogen bridges in hexafluoro-acetylacetone, trifluoroacetylacetone and some 3-substituted derivatives, J. Mol. Struct. THEOCHEM. 499 (2000) 21-34.

[10] H. Raissi, A. Nowroozi, M. Roozbeh, F. Farzad, Molecular structure and vibrational assignment of (trifluoroacetyl) acetone: A density functional study, J. Mol. Struct. 787 (2006) 148-162.

[11] M. Zahedi-Tabrizi, F. Tayyari, Z. Moosavi-Tekyeh, A. Jalali, S.F. Tayyari, Structure and vibrational assignment of the enol form of 1,1,1-trifluoro-2,4-pentanedione, Spectrochim. Acta Part A. 65 (2006) 387-396.

[12] R.N. Haszeldine, W.K.R. Musgrave, F. Smith, L.M. Turton, 130. Organic fluorides. Part VII. Coordination compounds of fluoroacetylacetones, J. Chem. Soc. Resumed. (1951) 609.

[13] J.P. Fackler, F.A. Cotton, 288. $\beta$-Diketones and their metal complexes. Part II. Acetylation of fluoroacetone to 1-fluoropentane-2,4-dione, J. Chem. Soc. Resumed. (1960) 1435-1438.

[14] P. Dirinck, M. Anteunis, C. Becu, Preparation of some 4- and 5-fluoromethylated 1,3-dioxans, J. Fluor. Chem. 2 (1973) 339-348. 
[15] S.F. Tayyari, F. Milani-Nejad, H. Rahemi, Structure and vibrational spectra of the enol form of hexafluoro-acetylacetone. A density functional theoretical study, Spectrochim. Acta Part -Mol. Biomol. Spectrosc. 58 (2002) 1669-1679.

[16] L. Evangelisti, S. Tang, B. Velino, B.M. Giuliano, S. Melandri, W. Caminati, Hexafluoroacetylacetone: A "rigid" molecule with an enolic $C_{s}$ shape, Chem. Phys. Lett. 473 (2009) 247-250.

[17] M.J. Frisch, G.W. Trucks, H.B. Schlegel, G.E. Scuseria, M.A. Robb, J.R. Cheeseman, G. Scalmani, V. Barone, B. Mennucci, G.A. Petersson, H. Nakatsuji, M. Caricato, X. Li, H.P. Hratchian, A.F. Izmaylov, J. Bloino, G. Zheng, J.L. Sonnenberg, M. Hada, M. Ehara, K. Toyota, R. Fukuda, J. Hasegawa, M. Ishida, T. Nakajima, Y. Honda, O. Kitao, H. Nakai, T. Vreven, J.A. Montgomery Jr., J.E. Peralta, F. Ogliaro, M. Bearpark, J.J. Heyd, E. Brothers, K.N. Kudin, V.N. Staroverov, R. Kobayashi, J. Normand, K. Raghavachari, A. Rendell, J.C. Burant, S.S. lyengar, J. Tomasi, M. Cossi, N. Rega, J.M. Millam, M. Klene, J.E. Knox, J.B. Cross, V. Bakken, C. Adamo, J. Jaramillo, R. Gomperts, R.E. Stratmann, O. Yazyev, A.J. Austin, R. Cammi, C. Pomelli, J.W. Ochterski, R.L. Martin, K. Morokuma, V.G. Zakrzewski, G.A. Voth, P. Salvador, J.J. Dannenberg, S. Dapprich, A.D. Daniels, Ö. Farkas, J.B. Foresman, J.V. Ortiz, J. Cioslowski, D.J. Fox, Gaussian 09 Revision B.01, Gaussian Inc., Wallingford CT, 2009.

[18] J. Schmidt, W. Polik, WebMO Pro. WebMO, LLC, Holland, MI, USA. Available from http://www.webmo.net., (accessed 13 Sep 2016).

[19] A.D. Becke, Density-functional exchange-energy approximation with correct asymptotic behavior, Phys. Rev. A. 38 (1988) 3098.

[20] A.D. Becke, Density-functional thermochemistry. III. The role of exact exchange, J. Chem. Phys. 98 (1993) 5648-5652.

[21] C. Lee, W. Yang, R.G. Parr, Development of the Colle-Salvetti correlation-energy formula into a functional of the electron density, Phys. Rev. B. 37 (1988) 785.

[22] G. Buemi, Intramolecular Hydrogen Bonds. Methodologies And Strategies For Their Strength Evaluation, in: Hydrog. Bond. Insights, Springer, Dordrecht, The Netherlands., 2006: pp. 51-108.

[23] F. Jensen, The magnitude of intramolecular basis set superposition error, Chem. Phys. Lett. 261 (1996) 633-636.

[24] G. Buemi, F. Zuccarello, Importance of steric effect on the hydrogen bond strength of malondialdehyde and acetylacetone 3-substituted derivatives. An ab initio study, Electron. J. Theor. Chem. 2 (1997) $302-314$.

[25] A.L. Andreassen, D. Zebelman, S.H. Bauer, Hexafluoroacetylacetone and hexafluoroacetic anhydride, J. Am. Chem. Soc. 93 (1971) 1148-1152.

[26] J.N. Woodford, Density Functional Theory and Atoms-in-Molecules Investigation of Intramolecular Hydrogen Bonding in Derivatives of Malonaldehyde and Implications for Resonance-Assisted Hydrogen Bonding, J. Phys. Chem. A. 111 (2007) 8519-8530.

[27] K. lijima, A. Ohnogi, S. Shibata, The molecular structure of acetylacetone as studied by gas-phase electron diffraction, J. Mol. Struct. 156 (1987) 111-118.

[28] K. lijima, Y. Tanaka, S. Onuma, Internal-Rotation of Trifluoromethyl Groups in Hexafluoroacetylacetone, J. Mol. Struct. 268 (1992) 315-318.

[29] C.L. Perrin, J.B. Nielson, "Strong" hydrogen bonds in chemistry and biology, Annu. Rev. Phys. Chem. 48 (1997) 511-544.

[30] Y. Mo, Can QTAIM Topological Parameters Be a Measure of Hydrogen Bonding Strength?, J. Phys. Chem. A. 116 (2012) 5240-5246.

[31] R.N. Pribble, F.C. Hagemeister, T.S. Zwier, Resonant ion-dip infrared spectroscopy of benzene(methanol $)_{m}$ clusters with $m=1-6$, J. Chem. Phys. 106 (1997) 2145-2157.

[32] H. Ratajczak, W.J. Orville-Thomas, Hydrogen-bond studies: Part I. The relation between vibrational frequencies and bond length in $\mathrm{OH}---\mathrm{O}$ hydrogen-bonded systems, J. Mol. Struct. 1 (1968) 449-461. 
[33] W. Caminati, J.-U. Grabow, The $\mathrm{C}_{2 v}$ Structure of Enolic Acetylacetone, J. Am. Chem. Soc. 128 (2005) 854-857.

[34] C. Chatterjee, C.D. Incarvito, L.A. Burns, P.H. Vaccaro, Electronic Structure and Proton Transfer in Ground-State Hexafluoroacetylacetone, J. Phys. Chem. A. 114 (2010) 6630-6640.

[35] I. Matanović, N. Došlić, Infrared Spectroscopy of the Intramolecular Hydrogen Bond in Acethylacetone: A Computational Approach, J. Phys. Chem. A. 109 (2005) 4185-4194.

[36] L.H. Spangler, Structural Information from Methyl Internal Rotation Spectroscopy, Annu. Rev. Phys. Chem. 48 (1997) 481-510.

[37] J.R. Durig, J.A. Hardin, H.V. Phan, T.S. Little, Conformational Analysis, Barriers To Internal Rotation, Ab Initio Calculations And Vibrational Assignment Of Fluoroacetone, Spectrochim. Acta Part Mol. Spectrosc. 45 (1989) 1239-1255. 